\title{
Evaluation of Polymer Flooding in a Highly Stratified Heterogeneous Reservoir. A Field Case Study.
}

\author{
JORGE ANDRES NAVAS GUZMAN ${ }^{1,2}$, BRUNO RAMON BATISTA FERNANDES ${ }^{1}$, MOJDEH \\ DELSHAD $^{1}$, KAMY SEPEHRNOORI $^{1}$, JOSE FRANCISCO ZAPATA ${ }^{2}$ \\ ${ }^{1:}$ Hildebrand Department of Petroleum and Geosystems Engineering, \\ The University of Texas at Austin, USA \\ ${ }^{2}$ Ecopetrol S.A., COLOMBIA
}

\begin{abstract}
Oil and gas companies are looking for proven hydrocarbon reserves from their mature drained reservoirs to extend the production and economic life of these fields. The chemical enhanced oil recovery (CEOR) is an attractive water-based EOR method for these mature fields. The polymer flooding (PF) is a widely applied process in reservoirs with low sweep efficiency after the water flooding (WF). The target Colombian field has one of the first polymer pilots in the region with positive results of oil recovery in "A" sands. Thus, the operator is interested in the expansion of PF for the same reservoir and even in deeper reservoir sands.

This paper focuses in the evaluation of different scenarios of PF for the producer in layers A and B with a mechanistic simulation model, thus obtaining new recommendations for the recovery strategy in the field. A sector model was constructed from a full field model using a commercial reservoir simulator to the in-house chemical flooding reservoir simulator: UTCHEMRS. This sector model was also migrated to a second commercial simulator allowing a performance comparison for these three simulators. UTCHEMRS model results were compared with the commercial simulators through the history matching (HM) phase. The primary and waterflood history match was in agreement with the field data.

Simulation results suggested that PF for the base case in " $\mathrm{A}$ " sands presented an incremental oil recovery of up to $12 \%$ additional to water flooding. Additionally, $\mathrm{PF}$ was extended to the lower layer "B" sand to investigate the potential of polymer injection. The PF injection in both reservoirs simultaneously loses sweep efficiency and decreases the oil recovery to about 3\%. However, a hypothetical case of new infill producer wells with the objective of testing the individual reservoir performance has revealed that PF is having significant upside from B sands as well.
\end{abstract}

Key-Words: - Colombian oil field, Reservoir simulation, Polymer flooding, Chemical enhanced oil recovery, Heterogeneity, Vertical efficiency.

Received: April 1, 2019. Revised: December 28, 2019. Accepted: January 3, 2020.

Published: January 12, 2020.

\section{Introduction}

Since the 1970's the global consumption of oil has begun to rise dramatically because its particular properties positioned this fossil fuel as a high energy density source in comparison with other energy sources [1]. The scarcity of new discoveries of conventional oil reservoirs and the ambitious task of meeting the growing energy demand has led to the search for novel technologies to improve oil recovery from the existing mature oil fields. As a result, during this same decade, Enhanced Oil Recovery (EOR) methods began to be applied as a series of advanced technologies that improve the oil production by lowering the mobility ratio (M) and/or the Interfacial Tension (IFT).

Throughout the history of Enhanced Oil Recovery (EOR) technology the injection of polymer has played an unquestionable role as an effective method of improving the mechanism(s) to extract oil from the reservoirs. This improved process is usually applied after a relatively short Water Flooding (WF). The characteristics of polymer are well-known in EOR industry. For instance, the viscosity increase of the driving phase (water) improves the sweep efficiency and the mobility control [2]. Consequently, the displacement of the oil phase by viscous polymer solution behaves as a piston like displacement, improving the effectiveness of the drive. In this work, the successful pilot of Polymer Flooding (PF) implemented in a heterogeneous reservoir called " $\mathrm{A}$ sands" is used as the basis for the optimization of production through EOR methods in $\mathrm{A}$ and $\mathrm{B}$ reservoirs. 
The target Colombian Field has one of the PF pilots with positive results in the area of MidMagdalena Valley Basin. After four years of continuous polymer injection in four injectors, this pilot has generated possibilities to evaluate the prospects of expansion and/or the implementation of this technology in another reservoir known as " $B$ sands." The main objective of this paper is to evaluate different scenarios of PF in the producing layers A and $B$. with a mechanistic chemical flooding reservoir simulator, thus obtaining new recommendations for the recovery strategy in the field. The results of these scenarios were evaluated to recommend the most prospective and reliable plan of EOR expansion and/or implementation [3].

\section{Background and context}

The Colombian field is located at the center-north of Colombia in the Mid-Magdalena Valley Basin between the eastern and central mountain ranges, bordered by the Magdalena River. Figure 1 gives a schematic of the location.
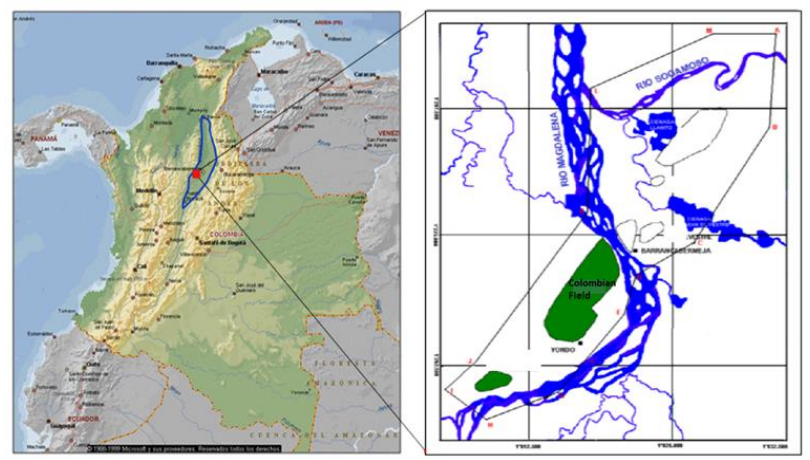

Figure 1. Location map of Colombian Field (modified from Gheneim et al. [4])

The main natural drive is solution gas with a weak water drive in the basal sands. The major reservoirs, which belong to the Tertiary age, are called A Sands the shallowest production layers, the $\mathrm{B}$ and $\mathrm{C}$ Sands are the deeper production reservoirs (see Figure 2). Those producing formations are product of fluvial currents of anastomosed type with high heterogeneity, mainly vertical and to a lesser extend laterally. The depths of the formations vary between 2200 and $5500 \mathrm{ft}$ in True Vertical Depth (TVD). From A to $\mathrm{C}$ sands there are 23 identified reservoirs with an approximate column of $3000 \mathrm{ft}$. Each formation is divided in sub-sands differentiated by shale bodies between them, as shown with details in Figure 2.

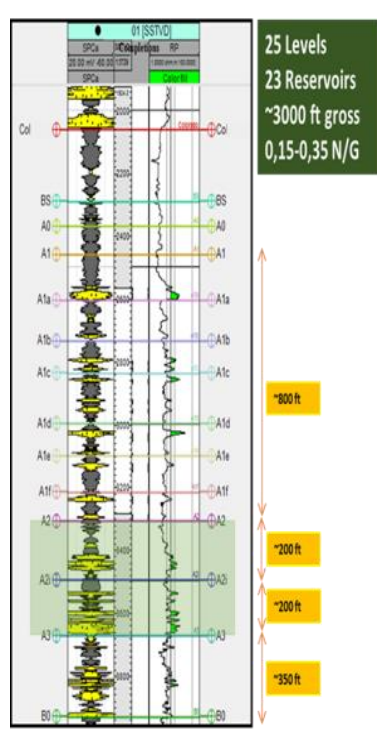

(a)

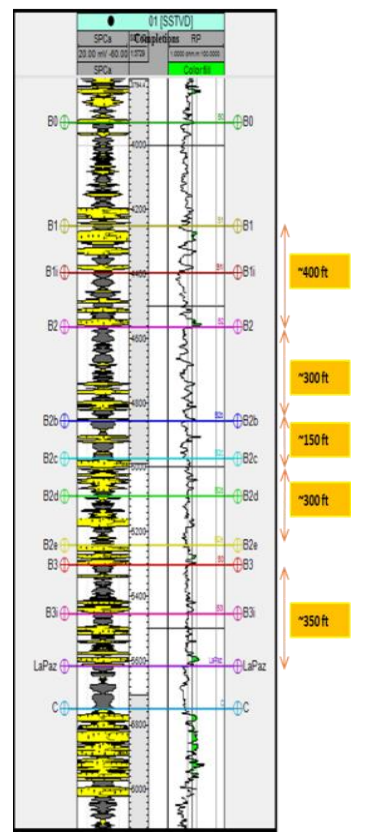

(b)

Figure 2. Log profile example of well in Colombian field. (a) A formation (b) B and C formations.

\subsubsection{Polymer pilot}

The secondary WF recovery applied in this Colombian field has been a successful project for more than 30 years. However, during these years of waterflooding operation, some limitations and operational issues were identified, such as thief zones or early water breakthrough, increased water cut and increase in sand production. Mostly the high mobility ratio of $\sim 20$ and the heterogeneous reservoir are the challenges that may cause suboptimum WF performance.

The high mobility ratio in A sands is due to the crude oil viscosity $(\sim 40-100 \mathrm{cP})$ and water viscosity $(\sim 1 \mathrm{cP})$ at reservoir conditions and the main cause of the poor sweep efficiency. Furthermore, the heterogeneity of the reservoir characterized by stratification and wide variations of permeability escalate the low volumetric and displacement efficiencies leading to low recovery factor. Consequently, this inefficiency leaves remaining oil represented in large pockets of crude behind [5]. The challenges associated to the water flooding reveal the need for reservoir management to plan new options that can mitigate these issues that can get worse without any additional effort. As a result, the polymer injection was selected among the different EOR technologies evaluated in a screening process. The polymer increases the viscosity of the injection water, in order to decrease the mobility ratio through the rheological properties of a non-Newtonian fluid [6]. Polymer can also act as a profile control agent to 
mitigate the heterogeneity and assist as water diversion into the unswept layers.

In November of 2014, through the addition of polymer to the four existing injectors 1313, 1222, 1304, and 1292, the first pilot of PF in the Colombian field began its operation. The well pattern was arranged by 4 injectors and 10 producers: 2 in the center area and 8 producers in the second line. In addition, there are 13 boundary injectors. Figure 3 shows the configuration of the pattern.

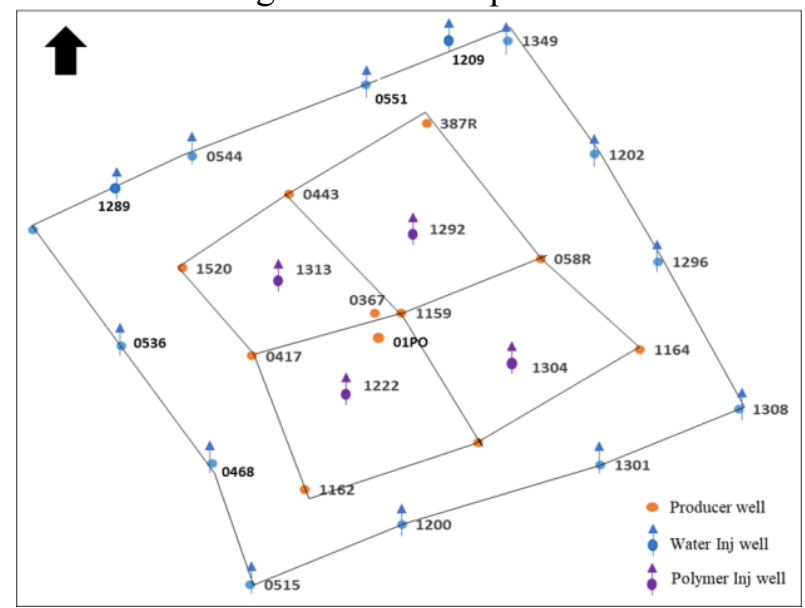

Figure 3. Location of each well of the polymer pilot pattern at $\mathrm{A} 2$ formation.

The conventional polyacrylamide HPAM Flopaam 5115 from SNF is the current polymer injected in the A sub-formations. Table 1 displays the properties of this polymer.

Table 1. Polymer properties - Flopaam 5115

\begin{tabular}{|c|c|}
\hline Molecular weight & 4-6 MM of Daltons \\
\hline Designed viscosity & $11.5 \mathrm{cP}$ \\
\hline Viscosity data at temperature & $46^{\circ} \mathrm{C}$ \\
\hline Filter ratio & 1.1 \\
\hline Goal concentration & $312 \mathrm{ppm}$ \\
\hline pH & $\begin{array}{c}5-9 @ 5 \mathrm{~g} / \mathrm{L} \\
0.8\end{array}$ \\
\hline $\begin{array}{l}\text { Relative density } \\
\text { Thermal stability }\end{array}$ & $\begin{aligned} & 0.8 \\
> & 150^{\circ} \mathrm{C}\end{aligned}$ \\
\hline $\begin{array}{c}\text { Total polymer injected daily } \\
\text { (bbl) }\end{array}$ & 1500 (4Wells) \\
\hline $\begin{array}{c}\text { Total polymer injected daily } \\
(\mathrm{kg})\end{array}$ & 70 (4 Wells) \\
\hline
\end{tabular}

\subsubsection{Reservoir heterogeneity}

Approximately $300 \mathrm{ft}$ represents the thickness of the $\mathrm{A} 2$ and A2i sands. However, the permeabilities range from $0.1 \mathrm{mD}$ to $1 \mathrm{D}$ in less than 30 vertical $\mathrm{ft}$. The flow capacity in each layer shows that there are high probabilities to find a thief zone or sub-units that can result in early breakthrough.

The process of polymer injection is highly related to the reservoir heterogeneity. In that line, this work is focused on the permeability heterogeneity, which is the function of the flow capacity [7]. Previously, it was mentioned that the effects of heterogeneity during the water injection become a challenge to the sweep efficiency. One method to quantify how heterogeneous is the formation associated with the permeability is through the Dykstra-Parsons Coefficient (VDP), which is an indicative of the variance of permeability [7]. From 0 to 1 the coefficient represents the most homogeneous close to zero and the most heterogeneous close to 1 . For the case of A2 the VDP is around 0.87 and A2 i is close to 0.86 ; for both cases, the permeability was evaluated only at the net pay thickness. Therefore, the wide range of permeability represents the highly heterogeneous sands.

The Polymer Flooding (PF) in Colombian Field aims to correct three main issues associated with the water flooding process. First, the channeling; according to the heterogeneity aspects, the sub-sands $\mathrm{A} 2$ and $\mathrm{A} 2 \mathrm{i}$ have large variations in vertical permeability.

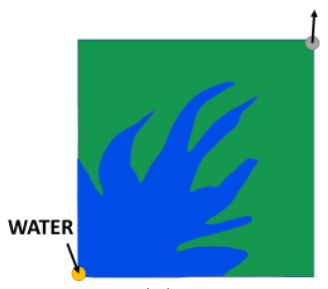

(a)

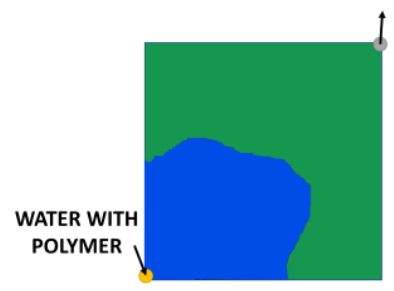

(b)
Figure 4. Schematic diagram comparison in a fivespot pattern between (a) areal sweep with water (b) areal sweep with polymer.

This heterogeneous formation boosts the water injection to channel quickly through the layers with highest permeabilities and reduced injection in the tight layers. The polymer reduces the permeability to water in the layers (permeability reduction, RK), triggering the cross-flow. In this way, the polymer flooding helps with vertical conformance reducing the early water production and forcing the injection water to move through the layers with lower permeability and potentially more remaining oil. Second, viscous fingering (mobility ratio); there is a direct relation between the viscous fingering and the mobility ratio. An adverse mobility ratio $M>1$ boosts the creation of viscous fingers that will channel into the oil. As a consequence, the water will breakthrough prematurely and leaving significant amount of oil behind or prolongs the waterflooding schedule (Figure 4). In addition, the heterogeneity in permeability also influences the formation of viscous fingers [8]. Adding polymer to water injection in the A sub-sands will increase the viscosity of the driving phase in order to suppress the fingers and 
consequently improve the areal sweep [5]. Ultimately, displacement difficulties generated by the capillary forces associated with the waterflooding. The PF will improve the areal efficiency of the displacement process.

\subsection{Sector Model}

The sector model was built by the reservoir engineering department of a Colombian Oil Company with the goal of simulating polymer injection through sub-sands A2 \& A2 $\mathrm{i}$ using the commercial simulator ECLIPSE-100 from Schlumberger, a black oil, three-dimensional, three phase, chemical flooding and fully-implicit simulator. The area of the sector model covers a northern portion of block VI of Colombian Field. As a result, this base case is the foundation of this work, which will be converted to UTCHEMRS, an in-house chemical flooding reservoir simulator from The University of Texas at Austin [9]. From the base model, new scenarios are generated and used for the optimization of the production in A sands. A similar study is done for B sands.

The geological model discretizes the domain with a corner-point geometry (CPG) with high vertical resolution due to the vertical heterogeneity. In order to represent reliably the reservoir complexity, 1336 grid cells in the $\mathrm{z}$ direction with an average cell thickness of $2.84 \mathrm{ft}$ are considered. In the $\mathrm{y}$ direction, there are 85 grid cells with an average cell width of $76.4 \mathrm{ft}$, and there are 71 grid cells with an average cell length of $91.8 \mathrm{ft}$ along the $\mathrm{x}$ direction. A total of $8,062,760$ cells are used, which 708,000 are active. In total, there are three geological formations divided into seven zones and subsequently twentyfive layers.

The History Match (HM) of the base case is from February 1985 to February 2018 of about 33 years. This HM includes the Water Flooding (WF) and the Polymer Flooding (PF), performed in the last four years of PF applied in the Colombian Field. During the development of the methodology section the HM results will be displayed including the simulation using another commercial reservoir simulator. INTERSECT a simulator from Schlumberger with recent CEOR model capabilities was also tested using the same sector model to have a comparison among several reservoir simulators. The model was transferred to and simulated with UTCHEMRS and INTERSECT for the HM, WF, and PF forecast.

\section{Methodology}

The evaluation of the PF performance in each reservoir is following the methodology described in Figure 5.

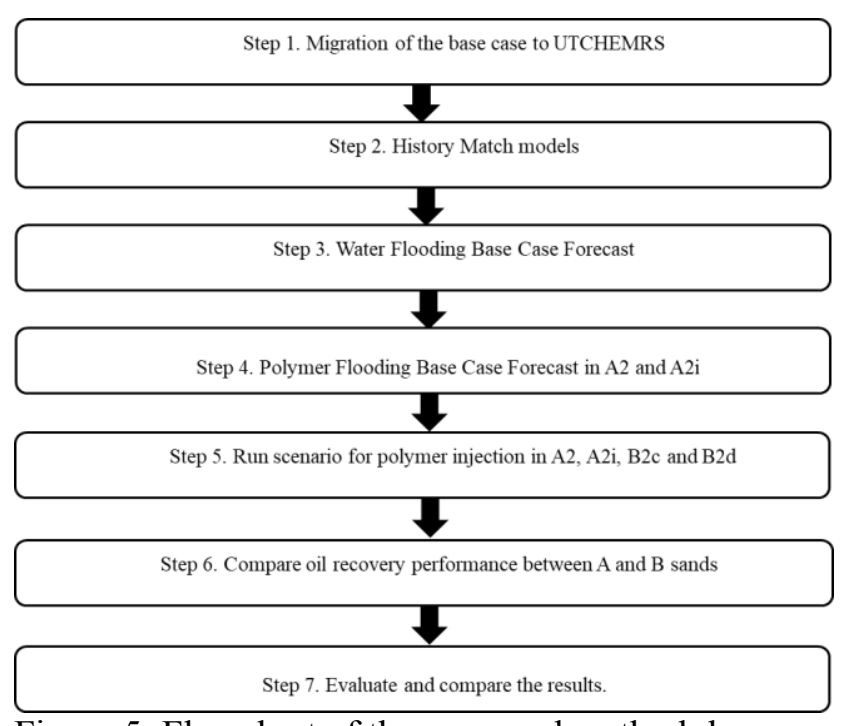

Figure 5. Flowchart of the proposed methodology.

\subsection{Migration to UTCHEMRS}

The data of geological grid, reservoir properties, producers, and injection wells were transferred to UTCHEMRS from the ECLIPSE base case. The initial goal was to compare the capabilities of the two simulators. The UTCHEMRS has advanced polymer and surfactant models, such as the effect of hardness (calcium + magnesium) on polymer viscosity and adsorption and improved polymer injectivity model that can add value when making field design recommendations. This migration is the base of new possible scenarios for testing the PF capabilities. Specifically, the transfer of the geological model, the dynamic model, and the polymer properties of the sector model is described as follows.

The conversion of the simulation deck is not restricted to the reformulation of data sets and keywords; it also requires careful analysis of physical models available in both simulators and data regression of raw data to the new simulator. The data reformulation includes the conversion of the reservoir geometry, reservoir properties, and well locations and their completion/perforation data. The geological model uses corner-point grid geometry, which is constructed following the complex geological features of the reservoir. Therefore, the migration of the static model is a task particularly challenging. Such complexities include changes in dip, azimuth, and thickness of the deposit layers, and truncations caused by faults.

There are reservoir properties that do not change with time, such as porosity or permeability (see Figures 6(a) and 6(c)); these collections of attributes are known as static model. On the other hand, the dynamic model is integrated by attributes that change according to production time, such as reservoir 
pressure or oil/water saturation (see Figures 6(b) and $6(d))$.

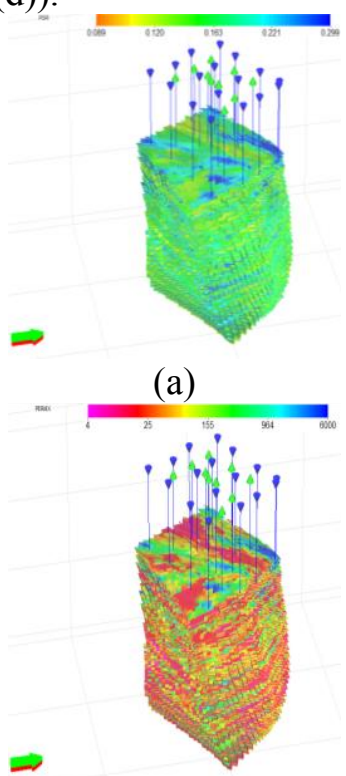

(c)

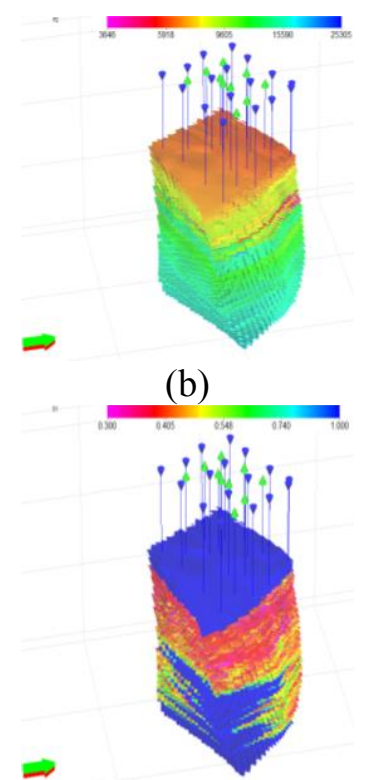

(d)
Figure 6. Grid properties migrated to UTCHEMRS. (a) Porosity (fraction) (b) Pressure (kPa) (c) Permeability $(\mathrm{mD})(\mathrm{d})$ Water saturation (fraction).

\subsection{History Match models}

This step shows the history match (HM) results for three different simulators. In this work the HM focuses on the PF history. Therefore, it starts from June 2014, which is five months before the first injection of polymer, to February 2018. Since the ECLIPSE HM begins on February 1985, it was necessary to run a restart case from June 2014 in order to compare the same period of time. The figures below show the HM results of ECLIPSE, INTERSECT, and UTCHEMRS compared to the field data.

The original HM model is controlled by liquid production rate. Same constraint was used for the other two simulators. According to the Figure 7, the results of oil rate HM differ among simulation results and the field data at the beginning of June 2014 and for the subsequent eight months. However, the similar responses created based on different assumptions and models, indicated a reliable HM. One reason for the differences between the field and simulation results might be related to the uncertainty in the geological modeling.

On the other hand, the remaining part, which is affected by PF, shows a similar tendency of oil production rate. There are some spikes in the field production data that the simulators cannot mimic in detail. Since the UTCHEMRS and INTERSECT reservoir models were generated from the ECLIPSE model, it is expected to have comparable results for all simulators. However, the UTCHEMRS model matches the field cumulative oil recovery only slightly better as shown in Figure 7 and Table 2 .

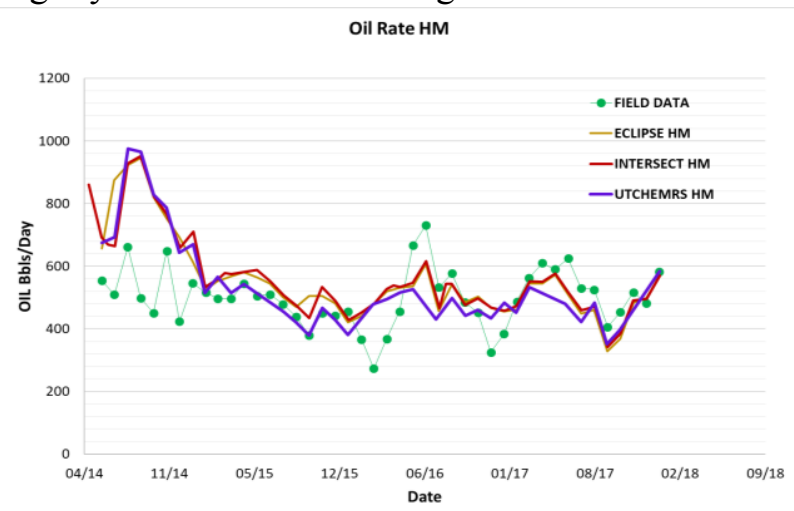

Figure 7. Oil rate History Match comparison.

Table 2. Comparative oil volumes as of January 2018.

\begin{tabular}{c|c|c|c}
\hline & $\begin{array}{c}\text { Cum Oil } \\
\text { (MMbbls) }\end{array}$ & $\begin{array}{c}\text { Volume } \\
\text { difference } \\
\text { (MMbbls) }\end{array}$ & $\begin{array}{c}\text { Difference } \\
\text { from the } \\
\text { reference } \\
(\%)\end{array}$ \\
\hline Field data & 0.669 & & \\
ECLIPSE & 0.739 & 0.071 & $9.5 \%$ \\
INTERSECT & 0.745 & 0.076 & $10.2 \%$ \\
UTCHEMRS & 0.731 & 0.062 & $8.5 \%$ \\
\hline
\end{tabular}

The HM performance in UTCHEMRS will be used as a foundation for the future simulation cases defined in the next steps of the workflow.

\subsection{Water Flooding HM and Base Case Forecast}

In order to determine the oil recovery by the PF process in $\mathrm{A} 2$ and $\mathrm{A} 2 \mathrm{i}$ sands, a hypothetical case was simulated without polymer injection during the HM. The WF simulation is a base for the next case of PF.

The Base Case is the forecast scenario without additional activity such as the drilling of new wells or the injection of a new EOR process. This case is keeping the activity before finishing the HM. In this work the forecast is extended for almost six years or 2129 days starting from February 2018 and finalizing on November 2023. The WF HM and forecast results are presented in Figure 8. 


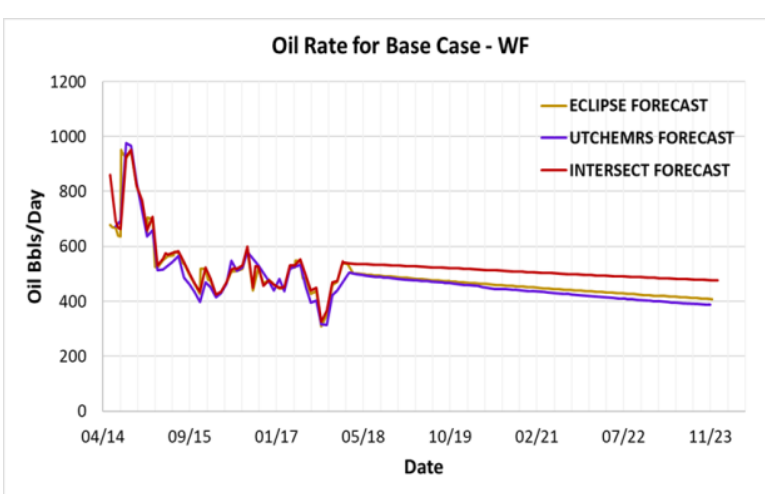

Figure 8. Oil rate for base case WF.

In general, the results of three simulators have similar tendency in oil production rate and cumulative oil recovered. These simulations show good agreement of both HM and forecast modes with confidence in the results. In the case of forecast, ECLIPSE is the reference point for the evaluation results considering that it is the original simulator of the sector model and it is the widely used commercial simulator. Table 3 reveals a difference of less than $7 \%$ among them.

Table 3. Comparative oil volumes HM and forecast simulations for WF as of December 2023.

\begin{tabular}{c|c|c|c}
\hline & $\begin{array}{c}\text { Cum Oil } \\
\text { (MMbbls) }\end{array}$ & $\begin{array}{c}\text { Volume } \\
\text { difference } \\
\text { (MMbbls) }\end{array}$ & $\begin{array}{c}\text { Difference } \\
(\boldsymbol{\%})\end{array}$ \\
\hline ECLIPSE & 1.694 & & \\
INTERSECT & 1.821 & 0.127 & $7.0 \%$ \\
UTCHEMRS & 1.655 & -0.039 & $-2.4 \%$ \\
\hline
\end{tabular}

\subsection{Polymer Flooding Base Case Forecast in A2 and A2i sands}

Using the Step 3 results, the PF base case is performed. The conditions for this scenario are defined as the same specifications at the end of the HM. The polymer is injected through the four injectors - with equal polymer concentration (300$400 \mathrm{ppm})$. The simulation results for the three simulators will be presented in the results section.

\subsection{Perform scenario for polymer injection in A2, A2i, B2c, and B2d sands.}

The positive results of $\mathrm{PF}$ in $\mathrm{A} 2$ and $\mathrm{A} 2 \mathrm{i}$ brings the possibility of testing the same technology in a reservoir structurally lower than A sands, called B sands. This step considers injecting polymer in A2, A2i, B2c, and B2d at same time. The purpose of this scenario is to evaluate the possibility of injecting polymer in both sands. The results will be appraised with the oil recovery comparison between this case and the case of the previous step.
According to the previous analyses of productivity done by the Colombian Company, the B2c and B2d sands are the most prospective layers at $B$ reservoir. In addition, the operator performed a polymer injectivity evaluation and selection study where a total of 8 polymers were tested. This fluidfluid study [10] includes test of viscosity performance, thermal/mechanical stability and filterability. One of the most compatible polymers that met the minimum conditions for injecting in " $\mathrm{B}$ " sands was selected as the conventional polyacrylamide Flopaam 5115 from SNF used for "A" sands. The fluid-rock study is still in process. Meanwhile, the same polymer concentration as in the "A" sand was used in UTCHEMRS. However, careful laboratory and field injectivity tests are required to adequately select the polymer type and concentration for the "B" sand.

\subsection{Comparison of oil recovery performance of $P F$ for $A$ and $B$ Sands}

The preceding step simulated the cases with A and B sands at the same time. However, the polymer injection process in each formation is likely different because the diverse conditions of rock and fluid properties. Table 4 presents the major properties comparison between $\mathrm{A}$ and $\mathrm{B}$ reservoirs.

Table 4. Reservoir and fluid data for A and B reservoirs.

\begin{tabular}{c|c|c}
\hline & A Sands & B Sands \\
\hline Porosity of Net Sand (\%) & 22 & 20 \\
Permeability Range of Net & $100-1000$ & $50-500$ \\
Sand (mD) & 21.5 & 23.7 \\
'API of Oil $^{\text {Datum (SS) (ft) }}$ & 3035 & 4015 \\
Reservoir Temp ( ${ }^{\mathbf{} F)}$ & 116 & 125 \\
Reservoir Pressure (psi) & 1510 & 1963 \\
Buble Pressure (psi) & 1228 & 1756 \\
\hline
\end{tabular}

The recovery evaluation will be through the drilling of three new oil producers at the north area of the current polymer pilot. Figure 9 illustrates the location of the proposed producers.

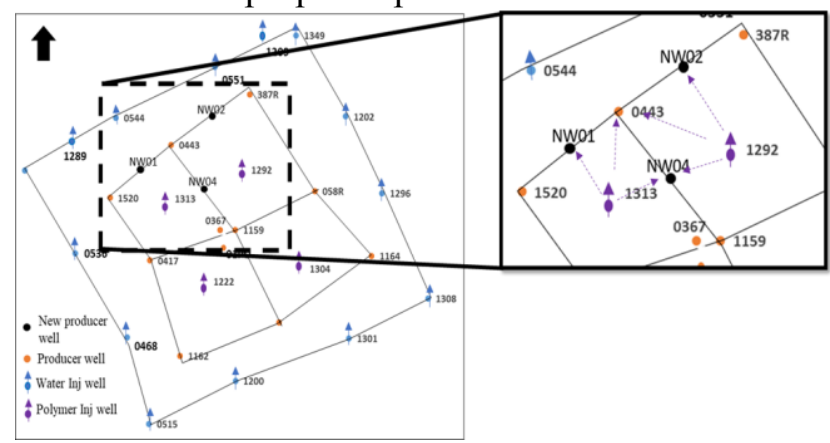

Figure 9. Schematic of the new wells for the selective polymer injection in A or B sands. Map at A sands depth. 
3.6.1 Injecting and Producing only in A Sands. Colombian field has a challenge associated to the uncertainty of the production potential by each reservoir as the oil production is not reliably allocated. The vast majority of the oil wells produce in commingled of up to three formations (A, B, and C). Therefore, these cases consider the squeeze of all completions unlike to A2 and A2i sands in the wells 443, NW01, NW02 and NW03 in order to ensure the selective affectation of PF to A sands. In addition, the polymer injectors 1292 and 1313 keep the injection through A2 and A2i.

\subsubsection{Injecting and Producing only in B Sands.}

These cases contemplate the squeeze of all completions unlike to B2 and B2i sands in the wells 443, NW01, NW02 and NW04 to ensure the selective injection of $\mathrm{PF}$ to $\mathrm{B}$ sands. In addition, the completions of $\mathrm{A} 2$ and $\mathrm{A} 2 \mathrm{i}$ will be closed and the $\mathrm{B} 2 \mathrm{c}$ and B2d sands will be open in the polymer injectors 1292 and 1313. The completion of the new wells and the interventions for the current wells will be performed starting March 2018.

\section{Results and Discussions}

\subsection{Base case forecast in A2 and A2i sands.}

Figure 10 displays the oil production results of all three reservoir simulators for the original case with original PF through the four injectors mentioned above. The well control for this scenario is the constant liquid rate production during $\mathrm{HM}$ and forecast.

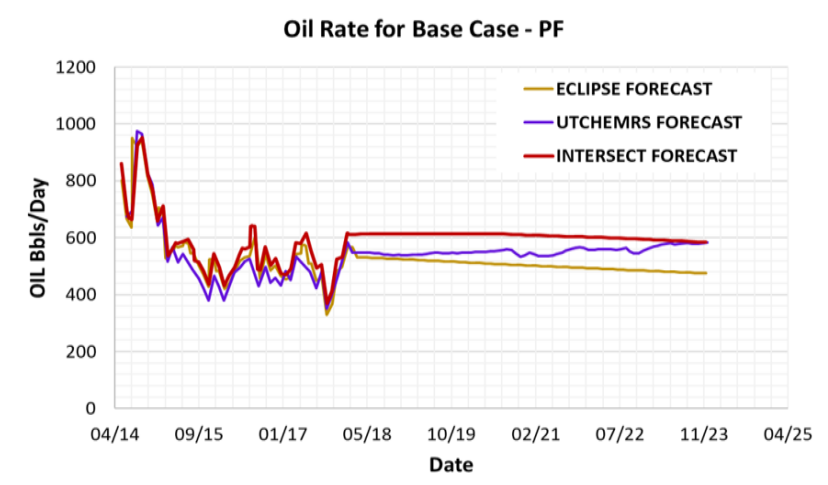

Figure 10. Oil rate for base case PF.

The most optimistic results are obtained from the INTERSECT simulation but very similar trend to ECLIPSE results. On the other hand, UTCHEMRS simulation has slightly different trend but the production data are in between ECLIPSE and intersect results. The cumulative oil production from UTCHEMRS increases with time with a closer agreement to ECLIPSE results. Table 5 is revealing that the cumulative oil of UTCHEMRS forecast is closer to the simulation results of ECLIPSE.

Table 5. Comparative PF oil volumes forecast for each simulator as of December 2023.

\begin{tabular}{c|c|c|c}
\hline & $\begin{array}{c}\text { Cum Oil } \\
\text { (MMbbls) }\end{array}$ & $\begin{array}{c}\text { Volume } \\
\text { difference } \\
\text { (MMbbls) }\end{array}$ & $\begin{array}{c}\text { Difference } \\
(\%)\end{array}$ \\
\hline ECLIPSE & 1.827 & & \\
INTERSECT & 2.140 & 0.313 & $14.6 \%$ \\
UTCHEMRS & 1.897 & 0.070 & $3.7 \%$ \\
\hline
\end{tabular}

\subsection{Polymer Flooding in A and B Sands}

The Colombian company is looking for new opportunities in this Colombian Field to increase the oil reserves and improve the company profitability. The B2c and B2d sands are part of the development plan in the near future because both sands are the most prospective layers after the A sands. Therefore, the evaluation of the PF application in B2c and B2d sands are the scope of this study. Knowing that there are only three current producer wells open in B sands.

The objective of this task is to evaluate the polymer injection in layers A2, A2i, B2c, and B2d simultaneously through the original four injectors shown in Figure 3. The case of commingled production is the most likely scenario in Colombian field due to the current production configuration.

Figure 11 and Table 6 show the comparison of two scenarios revealing that $\mathrm{PF}$ in both formations at same time is counterproductive reducing $3 \%$ the oil recovery in relation with the original case. The comparison begins from March 2018.

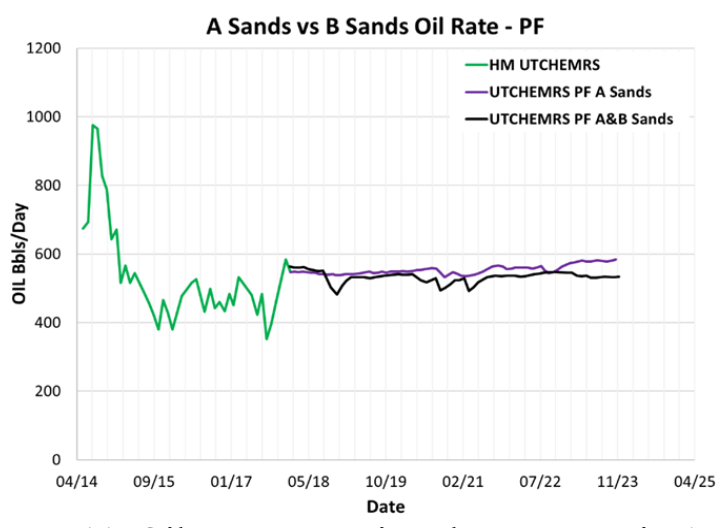

Figure 11. Oil rate comparison between $\mathrm{PF}$ in $\mathrm{A}$ sands and PF in both A and B sands. 
Table 6. Comparative oil volumes for PF in A vs. both A and B sands as of December 2023.

\begin{tabular}{c|c|c|c}
\hline & $\begin{array}{c}\text { Cum Oil } \\
\text { (MMbbls) }\end{array}$ & $\begin{array}{c}\text { Volume } \\
\text { difference } \\
\text { (MMbbls) }\end{array}$ & $\begin{array}{c}\text { Oil } \\
\text { recovery } \\
(\%)\end{array}$ \\
\hline $\begin{array}{c}\text { PF A } \\
\text { Sands }\end{array}$ & 1.166 & & \\
$\begin{array}{c}\text { PF A\&B } \\
\text { Sands }\end{array}$ & 1.136 & -0.030 & $-3 \%$ \\
\hline
\end{tabular}

An evident reason of this loss of productivity is the increasing of water production. Figures 12 and 13 denote the effect of PF for all wells and for a specific producer 417 , respectively.

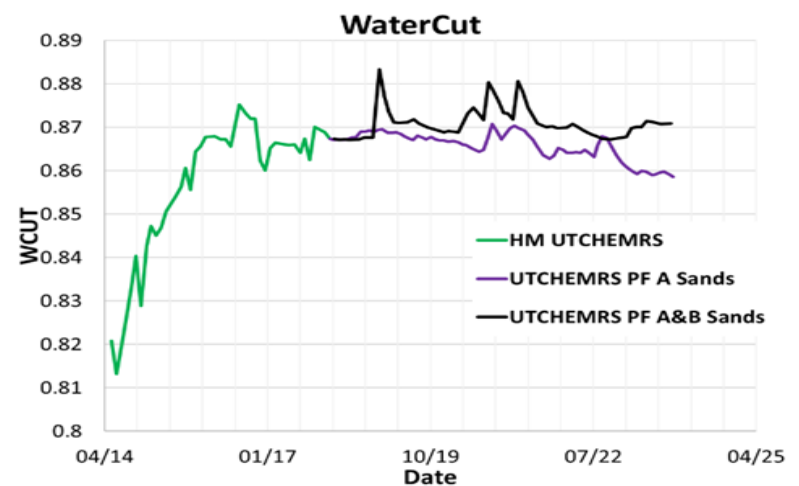

Figure 12. Comparative results of WF vs PF simulation of UTCHEMRS in water cut

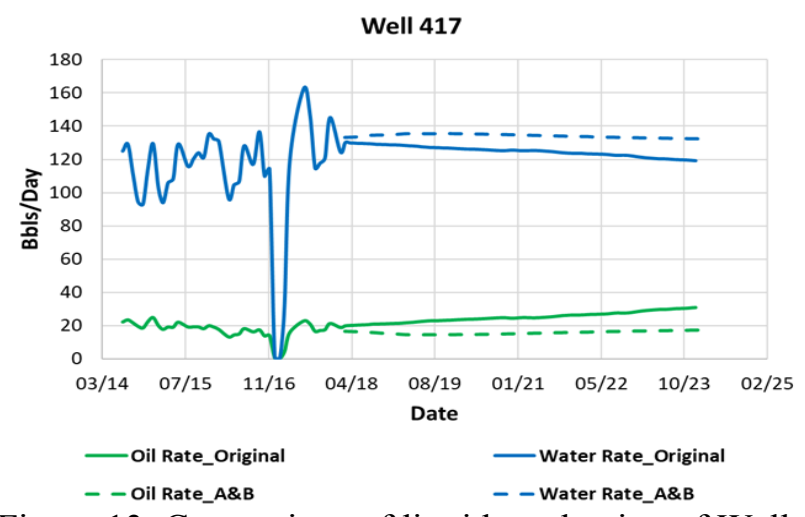

Figure 13. Comparison of liquid production of Well 417.

The water saturation maps after 1673 days (Sept. 2022) are presented below in Figure 14. It is clear that water saturation in A sands around most producer wells is lower indicating higher oil saturation (note, this model is not considering the gas phase). B sands map, has higher water saturations close to oil producers. In addition, the injector 1304 is located at the edge of an aquifer.

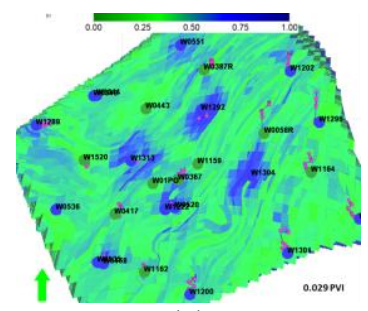

(a)

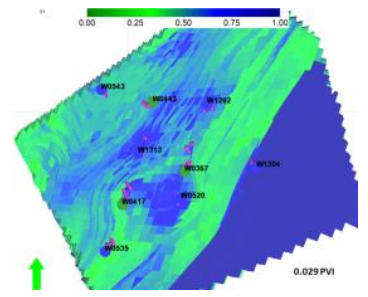

(b)
Figure 14. Comparative results at Sept. 2022. (a) Water saturation map for A sands (b) Water saturation map for B sands.

The results given by this case are considered nonconclusive due to the few wells currently operating in $\mathrm{B}$ sands in the pilot area and their locations in areas with likely high water saturations. Therefore, a new scenario is required to evaluate the real potential of $B$ sands. Consequently, the next step proposes cases with the addition of new infill wells and production from a single formation.

\subsection{Polymer Flooding Performance in A sands versus $B$ sands}

According to Figure 9 the well spacing reduction with the three new wells is at least half, changing from 200 to 100 meters approximately.

Figures 15 and 18 show the comparison between the WF and PF in two different stages of the simulation for A and B sands respectively. Map 15(a) depicts the consequence of WF in a hypothetical case without polymer injection during the entire history of the field; with the objective to see clearly the benefits of the PF. Map 15(b) shows the case with PF. The parts (c) and (d) are the cross-section SE-NW at deliberated region of the plane surface given in the (a) and (b) parts.

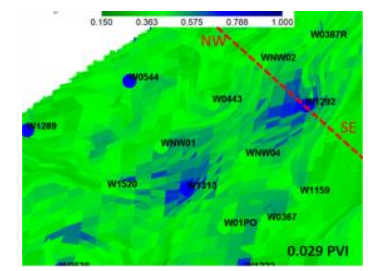

(a)

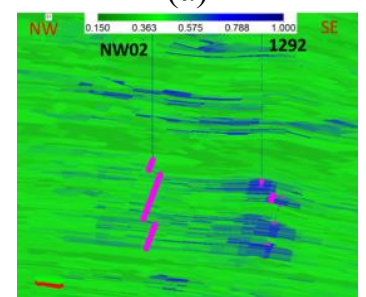

(c)

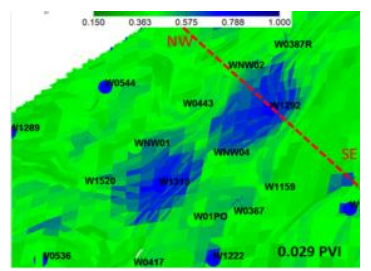

(b)

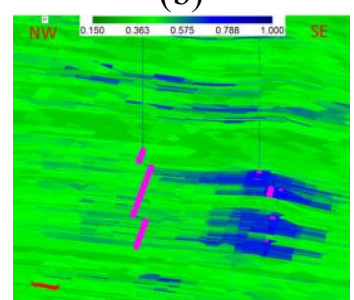

(d)
Figure 15. Water saturation maps for Only A at 122023 (a) Surface view at A sands for WF (b) Surface view at A sands for PF (c) Cross-section SE-NW for WF (d) Cross-section SE-NW view for PF. 
Figure 15(c) and (d) represent the connection between the Injector 1292 and the Producer NW02. The pink dots are the well completions. This figure gives the vertical permeability variations. For instance, the upper and one of the lowest injection completions are considered as thief layers. The profile of advance with WF shows the early arrivals of water to the producers due to those layers with high flow capacity. The early water breakthrough is a frequent event which have been proved in the oil wells in this Colombian field. As a consequence of this early arrival the WF turns to an inefficient process where the water goes for the layer with the lower pressure and already channelized sand, leaving behind important regions with significant remaining oil.

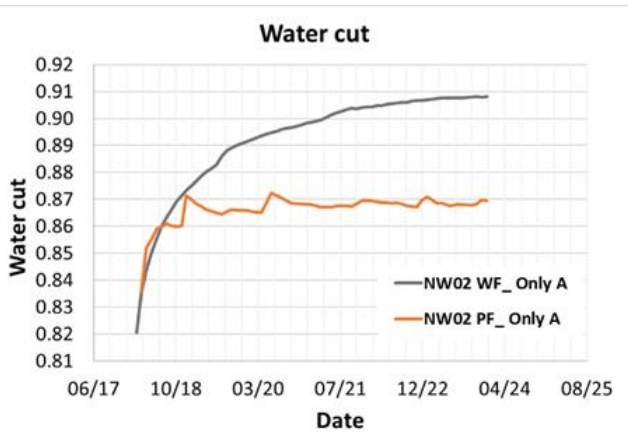

Figure 16. Water cut for WF vs. PF only in A sands - Well NW02

In Figures 16 and 19 the water cut of the NW02 is showing that most of the injected water is almost immediately produced, creating the typical channeling in this widely heterogeneous reservoir.

The effect of polymer injection in A and B sands is evident and demonstrate the improvement of the areal $E_{A}$ and vertical $E_{I}$ efficiency, due to the reduction of mobility ratio and subsequently the vertical crossflow. Causing a delay in the early arrival of water and raising oil production from layers with lower permeability. In Figures 15 and 18 (a) and (b) show the effect of polymer in a more homogenized advanced front sweeping a larger region than the WF. Additionally, Figures 15(c) and 15(d) show that with 0.017 PVI during the forecast, the neighbor area to the injector is having lower oil saturation. Thus, PF is mobilizing the remaining oil bypassed by the WF.

Figures 17 and 20 shows an illustration that describes the direct relation between the polymer concentration and the effect on the water/oil saturations in A sands.

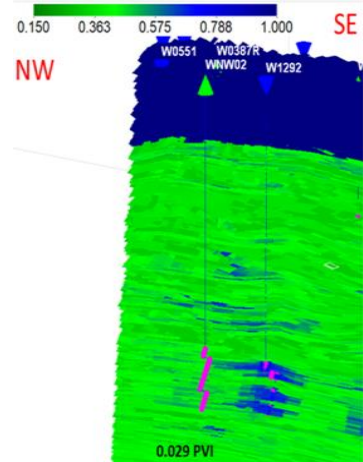

(a)

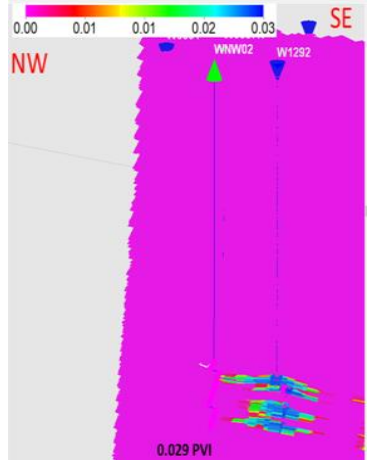

(b)
Figure 17. Vertical view maps for Only A at 122023 (a) Polymer concentration (b) Water saturation for $P F$.

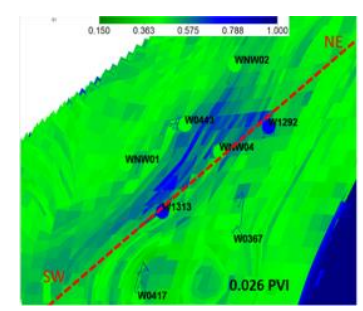

(a)

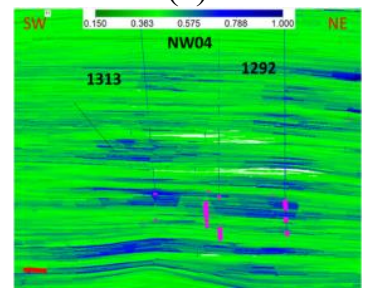

(c)

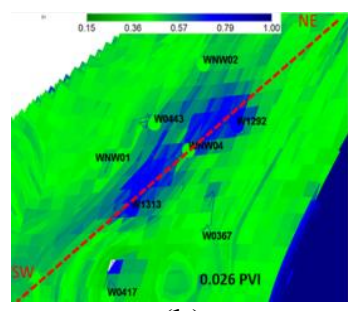

(b)

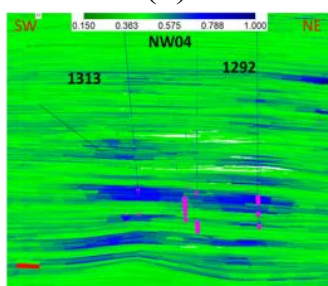

(d)
Figure 18. Water saturation maps for Only A at 122023 (a) Surface view at B sands for WF (b) Surface view at B sands for PF (c) Cross-section SE-NW for WF (d) Cross-section SE-NW view for PF.

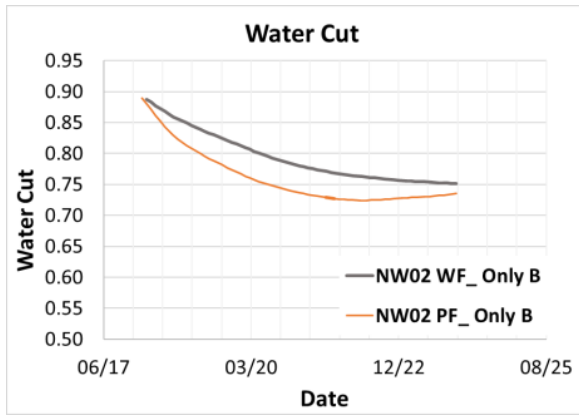

Figure 19. Water cut plots for WF vs PF only A sands Well NW02. 


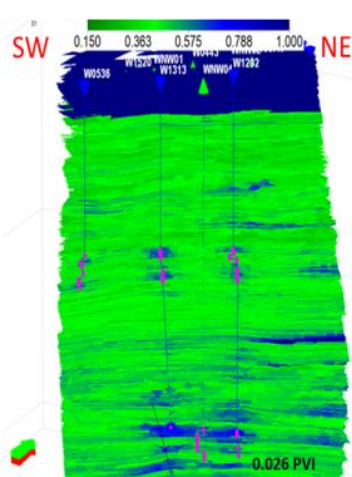

(a)

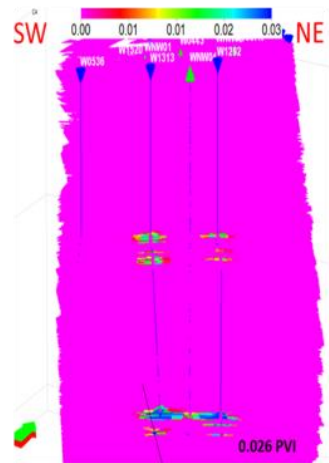

(b)
Figure 20. Vertical view maps for Only B at 122023 (a) Polymer concentration (b) Water saturation for PF.

The additional recovery for the new wells in both formations is positive. In the case of NW02 in A sand gives an additional oil recovery of $18 \%$ and for $\mathrm{B}$ sand is $14 \%$. After the analysis of UTCHEMRS results for the selective injection and single production in oil wells. The polymer effect in A and $\mathrm{B}$ sands is noticeable both areally and vertically. The new producers were close to the oil bank created from the previous polymer injected (apply for A sands) plus the polymer injected during the forecast. The significant oil production is likely due to oil bank breakthrough. Well locations in the non-drained area plus their locations with respect to the polymer front could be the key to formation of the oil bank. However, additional simulations are needed to strengthen this interpretation.

\section{Conclusions}

An ECLIPSE sector model of a field case was transferred to UTCHEMRS and INTERSECT reservoir simulators. The migration included the conversion of the reservoir geometry, reservoir properties, well locations, and well completion/perforation data. The results of three simulators were in fairly good agreement during HM and forecast for WF and PF. The close match for the base cases of three different simulators gave a confidence to evaluate additional flood scenarios using The University of Texas at Austin UTCHEMRS 2019.2.

The simulation of a hypothetical WF case without polymer injection during HM and forecast was the reference to evaluate the effectiveness of PF pilot in A sands. According to the results from three simulators, the $\mathrm{PF}$ in Colombian field give a significant oil recovery in the sub sands $\mathrm{A} 2$ and $\mathrm{A} 2 \mathrm{i}$ of A reservoir. With an additional recovery in a range of 7.3 to $12.8 \%$. Furthermore, the polymer injection delays the water breakthrough lowering the water cut by 2 to $5 \%$ for different simulators. The positive effect of PF on the incremental oil production makes this base case as a profitable project for the Colombian company with a positive NPV of 6.27 MMUSD.

The positive results of $\mathrm{PF}$ in $\mathrm{A} 2$ and $\mathrm{A} 2 \mathrm{i}$ sands have led to implementing the same technology in a reservoir structurally lower than "A" sands, called B sands. The results of injecting polymer in both reservoirs simultaneously were considered as nonconclusive due to the few wells currently in B sands in the pilot area and their locations in areas with likely high water saturations. The initial results reveal that this case seems a counterproductive scenario with 3\% lower recovery than the original case. Therefore, a new scenario was required to evaluate the true potential of B sands.

An additional case was designed with the purpose of testing the PF in B sands in three new infill wells drilled infill the injectors 1292 and 1313 and the producer Well 443. The additional wells reduce the spacing in half between the injector and the producer. The scenario proposes both production and the selective injection by single formation. The cases presented were: only production/injection in " $\mathrm{A}$ " sands and only production/injection in B sands. WF and $\mathrm{PF}$ scenarios were simulated to assess the incremental oil recovery for each reservoir.

The new infill producers NW01, NW02, and NW04, were tested with the polymer injection in each formation A and B sands. After the analysis of UTCHEMRS results for the selective injection and single production wells, the PF influence in both sands is significant both areally and vertically. This causes a delay in the early arrival of water and an increase of oil production from layers with lower permeability.

The 3D plots evidence the heterogeneous vertical permeability that influences the early breakthrough of water. Although, it was also possible to realize that polymer is helping with a more homogenized flood front sweeping a larger region than WF. This front might cause the formation of oil bank and delays the breakthrough of water. Therefore, reducing the water cut by $3 \%$ to $10 \%$. The oil recovery in those wells for "A" sand is in a range of 18.6 to $46 \%$ and for B sands of 14 to $42 \%$. The significant oil production is likely associated with an oil bank breakthrough. The new producers were near to the oil bank created for the previous polymer injected (apply for A sands) plus the polymer injected for the forecast simulation.

The well locations are not in a drained area plus their position respect to the polymer front could be the key to formation of the oil bank. The positive response of $\mathrm{PF}$ of $\mathrm{B} 2 \mathrm{c}$ and $\mathrm{B} 2 \mathrm{~d}$ sands of the new infill 
drills gives prospect to extend the polymer pilot to the lower sands. However, additional simulations are needed to strengthen this interpretation.

\section{References:}

[1] Bryce R., Power Hungry: The Myths of "Green" Energy and the Real Fuels of the Future, PublicAffairs, 2011.

[2] Lake L. W., Johns R., Rossen B., Pope G. A., Fundamentals of Enhanced Oil Recovery, Society of Petroleum Engineers, 2014.

[3] Navas J.A., Chemical Enhanced Oil Recovery Simulation in Highly Stratified Heterogeneous Reservoir. A Field Case Study, MS Thesis, The University of Texas at Austin, Austin, USA, 2019.

[4] Gheneim T., Azancot A., Acosta T., Zapata J.F., Chaparro C., Lobo A., Jimenez A. M., Perez G., Enhanced Oil Recovery in a High Stratigraphic Complex Reservoir: Casabe Project Case Study. In: Abu Dhabi International Petroleum Exhibition \& Conference. Abu Dhabi, UAE: Society of Petroleum Engineers; 2017. doi:10.2118/188555-MS.

[5] Sorbie K.S., Polymer-Improved Oil Recovery, CRC Press, 1991.

[6] Gogarty W.B., Mobility Control with Polymer Solutions, SPE Journal, Vol.7, No.2, 1967, pp. 161-173. doi: 10.2118/1566-B.

[7] Sahni A., Dehghani K., Prieditis J., Johnson S.G., Benchmarking Heterogeneity of Simulation Models. In: SPE Annual Technical Conference and Exhibition. Dallas, Texas: Society of Petroleum Engineers; 2005. doi:10.2118/96838-MS.

[8] Araktingi U.G., Orr F.M., Particle Tracking Computational Technique is Applied to Investigate how Viscous Fingers Form and Grow in Heterogeneous Porous Media, SPE Advanced Technology Series, Vol.1, No.1, 1993, pp. 71-80.

[9] Fernandes B.R.B., Development of Adaptive Implicit Chemical and Compositional Reservoir Simulators, PhD Dissertation, The University of Texas at Austin, Austin, USA, 2019.

[10] ICP, Experimental evaluation and selection of polyacrylamide base polymers, 2019. 